\title{
A Rare Skin Lesion During Pregnancy: Localized Cutaneous Leishmaniasis
}

\author{
Cihan ÇETİN1, Selim BÜYÜKKURT¹, Fatih KÖKSAL², Tuncay ÖZGÜNEN1 \\ Adana, Turkey
}

\begin{abstract}
Leishmaniasis is an infectious disease that is spread by phlebotomine sand flies. These flies cause infections called cutaneous and/or visceral leishmaniasis in humans. In this paper, we present a pregnant patient who was diagnosed with localized cutaneous leishmaniasis, a localized form of the disease, and the treatment we applied to the patient. The patient was given systemic amphotericin-B treatment, however the immunosuppressive state of pregnancy and the diabetes of the patient complicated the treatment. Although the size of the lesion regressed during pregnancy, we could not completely cure the disease.
\end{abstract}

Keyword: Leishmania, Leishmaniasis, Cutaneous, Amphotericin B, Pregnancy, Leishmania infantum

Gynecol Obstet Reprod Med 2016;22(2):102-104 DOI: 10.21613/GORM.2016.480

\section{Introduction}

There are various skin lesions that can be encountered during pregnancy. Some of these are specific to pregnancy whereas others are non-specifically seen during pregnancy. Non-specific lesions include infections, malignancy (benign or malign), rashes etc. One of the rare skin infections is cutaneous leishmaniasis that is caused by leishmania spp.

Infections caused by leishmania spp (L. major, L. infantum etc.) are named as visceral, cutaneous and mucocutaneous leishmaniasis (1). Cutaneous leishmaniasis that is frequently caused by L. major, L. tropica and L. mexicana, is a serious vector-borne dermal infection. Leishmania parasites are spread by the bite of phlebotomine sand flies. There are two types: localized and diffuse cutaneous leishmaniasis. The type of the disease differs among patients depending on the immunity of the host and virulence of the pathogen. Localize cutaneous leishmaniasis (LCL), usually begins with a pink plaque on open sites of the body for fly bites and later changes into a centrally ulcerated nodules with endured borders. The surface

${ }^{1}$ Çukurova University School of Medicine Department of Obstetrics and Gynecology, Adana

${ }^{2}$ Çukurova University School of Medicine Department of Medical Microbiology, Adana

Address of Correspondence:

Cihan Çetin

Cukurova University School of Medicine Department of Obstetrics and

Gynecology, Adana

cihancetin00@gmail.com

Submitted for Publication:

02. 02.2015

Accepted for Publication:

21. 05.2015 of the ulcer is usually covered with a hyperkeratotic scar and thick yellow-white fibrinous material. Lesions can be solitary or multiple. Frequently, lesions are secondarily infected by bacteria and this complicates the treatment.

Differential diagnosis for these lesions include bacterial infections, cutaneous myasis, pyoderma gangrenosum, ecthyma, cutaneous malignancies, sarcoidosis, cutaneous tuberculosis, various fungal infections etc.

Localize cutaneous leishmaniasis has been reported rarely during pregnancy. The immunosuppressive state of pregnancy aggravates the course of the disease and complicate the treatment. In this paper, we aimed to report a pregnant patient with the complaint of a persisting ulcerated lesion, whom we later diagnosed LCL.

\section{Case Report}

31 years old G1P0 patient admitted to Çukurova University School of Medicine antenatal clinic with the complaint of a skin lesion on her left leg that was persisting for six months. Patient was living in the city of Adana, which is considered as an endemic area for cutaneous leishmaniasis (2). Medical history revealed uncontrolled type II diabetes mellitus. On her left leg there was crusted purplish plaque with erythematous borders (Figure 1). Pathognomonic Leishmania bodies (Figure 2) and staphylococci as a sign of secondary bacterial infection were seen on the smear taken from the lesion. Furthermore with the use of PCR-RFLP assay of the ITS1 genes, Leishmania infantum was identified as the subspecies. 


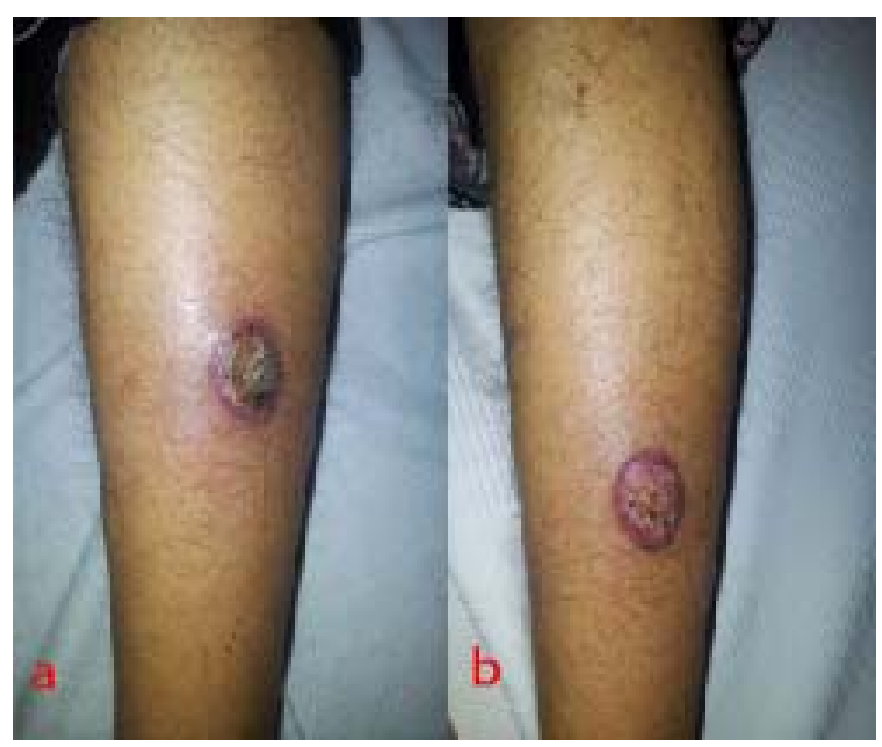

Figure 1: Photograph of the lesion a) before, b) after one week treatment.

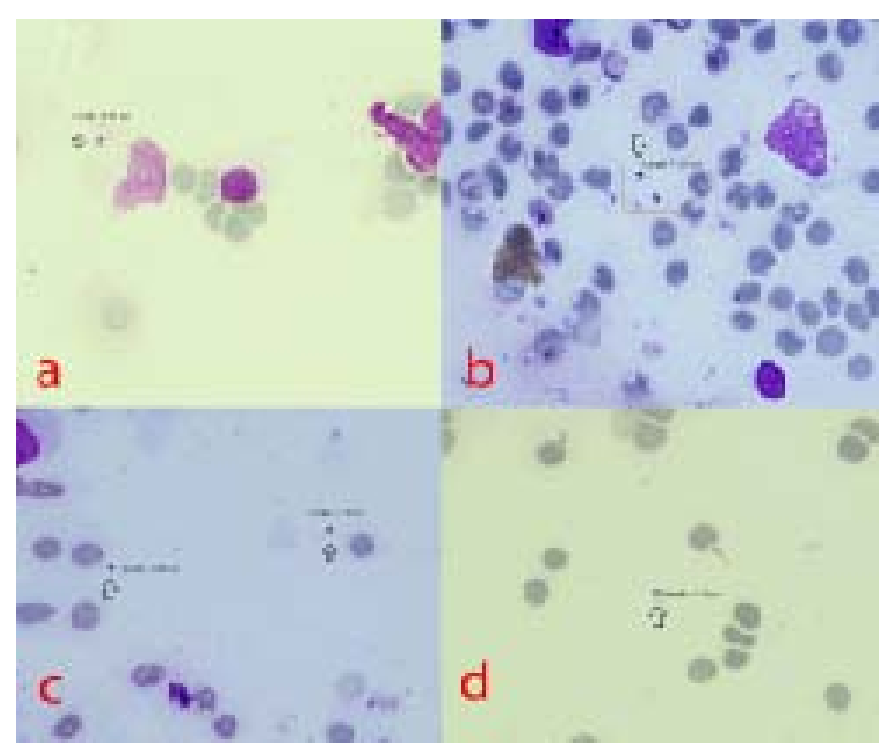

Figure 2: Pathognomonic Leishmania bodies on the smear (x1000 magnification, Giemsa stain)

Patient was given mupirocin ointment for the treatment of secondary bacterial infection together with amphotericin-B $1 \times 240 \mathrm{mg}$ IV for seven days. Blood glucose regulation was performed with insulin injections. Despite some regression in the size of the lesion, the lesion could not be completely cured during pregnancy. Patient delivered a healthy boy via cesarean section at 37 weeks of gestation due to breech presentation and premature rupture of the membranes. After the delivery, patient was lost to follow-up. Therefore, we were unable to evaluate the lesion after delivery.

\section{Discussion}

Pregnancy has an increased tendency for intracellular infections due to decreased Th1/Th2 ratio (3). These infections are caused by bacteria like $M$. tuberculosis, C. trachomatis and protozoan like Leishmania.

There are various studies in the literature showing the decreased immune response to Leishmania infections during pregnancy $(4,5)$. These studies showed that Leishmania-infected pregnant C57BL/6 mice developed larger lesions, harbored increased parasite burdens and expressed less IFN- $\gamma$ but increased levels of IL-4, IL-5 and IL-10 as compared to nonpregnant controls. Shifting to type 2 responsiveness in Th1/Th2 ratio complicates the treatment of this infection. Existing co-morbidities like diabetes, immunosuppressive drug use, connective tissue diseases further complicates the infection. During pregnancy, especially together with these states that increase the complication rates, the signs of the infection may be atypical and the diagnosis may be even more difficult (6).

The presentation of the lesions may be well-demarcated ulcers with raised borders or in a cauliflower appearance, which may also raise concern for other diseases, such as other skin infections and malignancies (1). The most important feature that should make clinicians suspicious of LCL, is the area that the patient lives. For patients living in the endemic areas, like tropics, subtropics and southern Europe; LCL should always be kept in mind, in cases of cutaneous lesions.

Although LCL is not linked to a specific fetal anomaly, it is shown to increase the risk of preterm birth, abortion and fetal death in animal studies (3). It is also reported to increase the rate of preterm birth and stillbirth in humans (1). However, in our case, patient delivered a term healthy baby.

The treatment of LCL consists of local, oral or parenteral drugs. These drugs include amphotericin-B, antimony compounds, paromomycin and miltefosine (1). Of these drugs, the safest during pregnancy is amphotericin-B. Others are teratogenic and counter indicated during pregnancy $(7,9)$. In our case, we used parenteral amphotericin-B; however, amphotericin-B was not effective to cure the lesion completely.

Unfortunately, there are not enough studies showing the optimal treatment for LCL during pregnancy, yet. However, taking into consideration from our knowledge from non-pregnant patients and teratogenity of the available drugs, currently, safest treatment approach for these patients during pregnancy seems to be systemic amphotericin-B and/or local treatment modalities.

Local treatment modalities include thermotherapy, cryotherapy, electrocauterization with or without $0.045 \%$ pharmaceutical chlorite (DAC N-055) $(10,11)$. These can be used during the follow-up management of residual lesions that are not fully healed after systemic treatment. In addition, these are (DAC N-055 is not studied enough for use during pregnancy) acceptable for use during pregnancy and breast 
feeding. Other local treatment approaches include intralesional pentavalent antimony, topical paromomycin and photodynamic therapy (12-14). However, our patient was lost to follow-up after delivery, so we were unable to apply and evaluate these treatment modalities.

Especially, at endemic sites, this infection, which can be encountered during pregnancy, should be kept in mind, and should not regarded as a simple skin infection. By this way, early diagnosis may prevent the treatment failure. Immunosuppressive state of pregnancy and comorbidities like diabetes make the treatment even more difficult. Indeed, in our case, despite adequate parenteral treatment during pregnancy, we were unable to completely cure the disease.

\section{References}

1. Goto H, Lauletta Lindoso JA. Cutaneous and mucocutaneous leishmaniasis. Infect Dis Clin North Am 2012; 26(2):293-307.

2. Gürel MS, Yeşilova Y, Olgen MK, Ozbel Y. Cutaneous leishmaniasis in Turkey. T Parazitol Derg 2012;36(2): 121-9.

3. Gabbe SG, Niebyl JR, Simpson JL, Landon MB, Galan HL, Jauniaux ERM, Driscoll DA. Obstetrics Normal and Problem Pregnancies. $6^{\text {th }}$ ed. Philadelphia, Elsevier 2012.

4. Arinola OG, Louis JS, Tacchini-Cottier F, Aseffa A, Salimonu LS. Pregnancy impairs resistance of C57BL/6 mice to Leishmania major infection. Afr J Med Med Sci 2005;34(1):65-70.

5. Krishnan L, Guilbert LJ, Russell AS, Wegmann TG, Mosmann TR, Belosevic M. Pregnancy impairs resistance of $\mathrm{C} 57 \mathrm{BL} / 6$ mice to Leishmania major infection and causes decreased antigen-specific IFN-gamma response and increased production of $\mathrm{T}$ helper 2 cytokines. J Immunol 1996;156(2):644-52.

6. Conceicao Silva F, Morgado FN, Pimentel MI, e Vasconcellos Ede C, Schubach AO, Valete-Rosalino CM, et al. Two women presenting worsening cutaneous ulcers during pregnancy: diagnosis, immune response, and follow-up. PLoS Negl Trop Dis 2013;7(12):e2472.
7. Morgan DJ, Guimaraes LH, Machado PR, D'Oliveira A, Jr., Almeida RP, Lago EL, et al. Cutaneous leishmaniasis during pregnancy: exuberant lesions and potential fetal complications. Clin Infect Dis 2007;45(4):478-82.

8. Avila-Garcia M, Mancilla-Ramirez J, Segura-Cervantes E, Farfan-Labonne B, Ramirez-Ramirez A, GalindoSevilla N. Transplacental transmission of cutaneous Leishmania mexicana strain in BALB/c mice. Am J Trop Med Hyg 2013;89(2):354

9. Alvar J, Croft S, Olliaro P. Chemotherapy in the treatment and control of leishmaniasis. Adv Parasitol 2006;61:22374 .

10. Jebran AF, Schleicher U, Steiner R, Wentker P, Mahfuz F, Stahl HC, et al. Rapid healing of cutaneous leishmaniasis by high-frequency electrocauterization and hydrogel wound care with or without DAC N-055: a randomized controlled phase IIa trial in Kabul. PLoS Negl Trop Dis 2014;8(2):e2694

11. Stahl HC, Ahmadi F, Schleicher U, Sauerborn R, Bermejo $\mathrm{J}$, Amirih $\mathrm{M}$, et al. A randomized controlled phase IIb wound healing trial of cutaneous leishmaniasis ulcers with $0.045 \%$ pharmaceutical chlorite (DAC N-055) with and without bipolar high frequency electro-cauterization versus intralesional antimony in Afghanistan. BMC Infect Dis 2014;14(1):619.

12. Uzun S, Durdu M, Culha G, Allahverdiyev AM, Memisoglu HR. Clinical features, epidemiology, and efficacy and safety of intralesional antimony treatment of cutaneous leishmaniasis: recent experience in Turkey. J Parasitol 2004;90(4):853.

13. Kim DH, Chung HJ, Bleys J, Ghohestani RF. Is paromomycin an effective and safe treatment against cutaneous leishmaniasis? A meta-analysis of 14 randomized controlled trials. PLoS Negl Trop Dis 2009;3(2):e381.

14. Asilian A, Davami M. Comparison between the efficacy of photodynamic therapy and topical paromomycin in the treatment of Old World cutaneous leishmaniasis: a placebo-controlled, randomized clinical trial. Clin Exp Dermatol 2006 Sep;31(5):634-7. 